FACULDADE DA AMAZONIA

CURSO DE ZOOTECNICA

$1^{\mathrm{a}}$ TURMA $8^{\circ}$ PERIODO

\title{
ASPECTOS RELACIONADOS À IMPLANTAÇÃO E DESENVOLVIMENTO DA PISCICULTURA
}

MARIA BEATRIZ KOMPIER

Vilhena

2012 
MARIA BEATRIZ KOMPIER

\section{ASPECTOS RELACIONADOS À IMPLANTAÇÃO E DESENVOLVIMENTO DA PISCICULTURA}

Monografia apresentada à Coordenação de Graduação, da Faculdade da Amazônia, como requisito parcial para obtenção do grau de Bacharel (Especialista) Zootecnia.

Orientadora: Profo (a) Ana Flavia Royer Co-orientador: Rômulo Gonçalves Costa Junior Co-orientadora: Pamela Souza de Pietro

VILHENA

2012 
Dedico este trabalho ao meu pai 
Agradeço primeiramente ao meu Senhor todo poderoso criador do céu e da terra, Deus pela minha vida, a minha família que sempre esteve ao meu lado. Em especial a minha mãe Maria Dolores, pelas suas orações e conselhos, os meus irmãos Martinus Kompier e Gabriel Kompier, pelo apoio e paciência. A Cida Alencar e Waldir Junqueira, pois sem eles nada disso seria possível. Aos meus amigos e colegas de faculdade em especial Rômulo Junior, Mariana da Silva, Keuciane Saibel e Ana Flávia Royer pela força que me deram nos momentos de alegria e tristezas. Aos meus professores e mestres pela dedicação e compreensão. 
"Se todos te abandonaram e se você hoje se sentir sozinho, então saiba é à hora de estar a sós com Deus..."

(Autor Desconhecido) 


\section{RESUMO}

Kompier, Maria Beatriz. Aspectos Relacionados à implantação e desenvolvimento da Piscicultura, 33, trabalho de conclusão de curso de Graduação, Faculdade da Amazônia, Vilhena 2009.

No intuito de contribuir para a implantação e bom desenvolvimento da piscicultura, o presente trabalho teve como objetivo mostrar que, sua implantação deve ser bem planejada e precedida de estudos e pesquisas que indiquem, com segurança, os melhores sistemas de produção a ser utilizado o tipo de espécie a se escolher e quais os principais manejos dentro de uma piscicultura, através de algumas práticas de manejo diário, que às vezes passam despercebidas. Mostrando que adoção de boas práticas de manejo e de um programa de gestão de qualidade é um caminho para o aumento da produtividade e lucratividade.

PALAVRAS-CHAVE: Piscicultura, Manejo, Planejamento 


\section{SUMÁRIO}

\section{RESUMO}

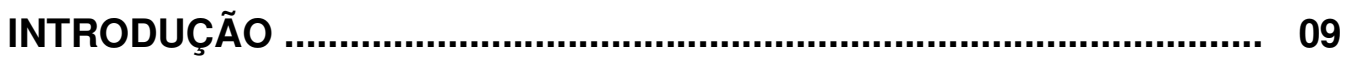

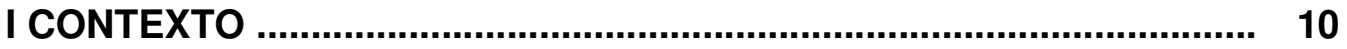

II REVISÃO TEÓRICA

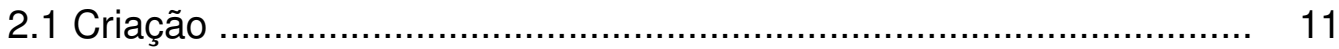

2.2 Escolha da Espécie ............................................................ 12

2.3 Sistema de Criação ……………………………………......... 13

2.3.1 Sistema Extensivo ................................................................. 13

2.3.2 Sistema Semi-Intensivo …………………….......................... 14

2.3.3 Sistema Intensivo ............................................................. 14

2.3.4 Sistema Super-Intensivo ........................................................ 15

2.4 Viveiros e Tanques ............................................................. 15

2.4.1 Sistema de Abastecimento e Drenagem …………..................... 17

2.5 Manejo dos Tanques ............................................................ 18

2.5.1.1 Qualidade da Água ........................................................ 18

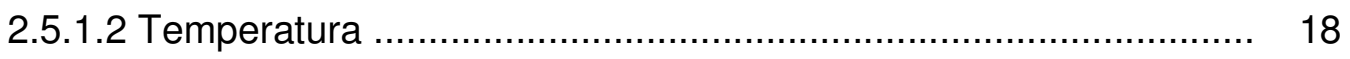

2.5.1.3 Oxigeno Dissolvido ......................................................... 19

2.5.1.3 Gás Carbônico................................................................... 19

2.5.1.4 Transparência ............................................................... 20

2.5.1.5 Potencial Hidrogênio ………….......................................... 20

2.5.1.6 Alcalinidade ................................................................. 21

2.5.2 Calagem e Adubação ............................................................. 22

2.5.3 Densidade e Estocagem .......................................................... 23

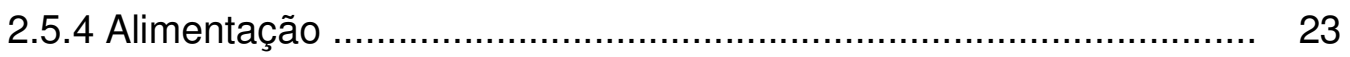

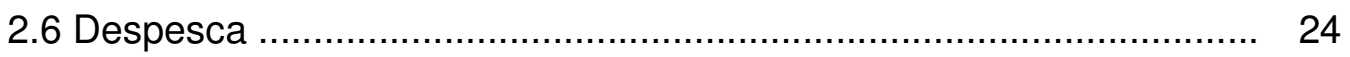

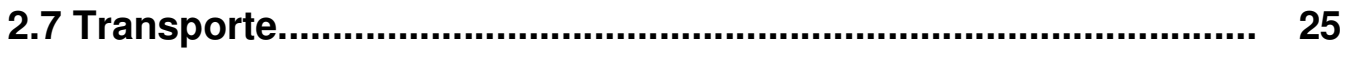

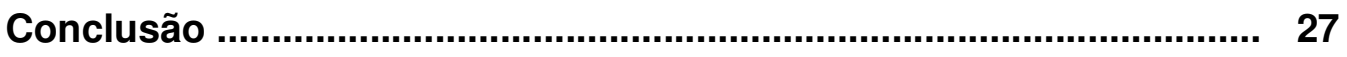

REFERÊNCIAS BIBLIOGRÁFICAS ............................................... 28 


\section{INTRODUÇÃO}

O Brasil com seu clima, diversidade de espécies, quantidade de água, tipo e extensão de solo, assim como a facilidade de acesso aos locais de produção, apresenta-se como uma das maiores potencialidades do mundo para 0 desenvolvimento da atividade piscícola (KUBITZA, 2007).

A piscicultura é uma atividade zootécnica cujo objetivo é a criação de peixes, monitorada através do manejo, reprodução, crescimento, alimentação e sanidade (PEZZATO, 1995).

Constitui-se de um moderno sistema de produção agropecuária. Como tal, para obter os lucros esperados, devem-se empregar métodos adequados e modernos. Baseados em princípios científicos, ecológicos, tecnológicos e econômicos (HEPHER \& PRUGININ, 1985).

Dentre suas vantagens está à capacidade de alta produção por área e a viabilidade econômica, quando comparada a outras atividades. Isso devido ao rápido capital de giro e grande importância social (PEZZATO, 1995).

É uma atividade em ascensão dentro do setor agropecuário do Estado de Rondônia, por ser uma importante alternativa para as pequenas propriedades. Porém, como ocorre com todas as novas opções de produção, sua implantação deve ser bem planejada e precedida de estudos e pesquisas que indiquem, com segurança, os melhores sistemas de produção a serem utilizados. (MARTINS et al., 2003;). Caso contrário, ao invés de promover o desenvolvimento regional, poderá resultar em falta de estímulo a novos investimentos e em abandono de unidades de produção. (HERMES et al., 2002)

No entanto, para dar continuidade aos avanços positivos conquistados até 
o momento, torna-se necessário um aperfeiçoamento de técnicas adequadas as diversas condições ambientais existentes no país (KUBITZA, 1999). 


\section{I - CONTEXTO}

A piscicultura, entendida como produção de peixes é uma atividade importante e viável economicamente. O Brasil tem um dos maiores potenciais do mundo para o desenvolvimento da piscicultura, particularmente devido ao seu clima, diversidade de espécies, quantidade de água, tipo e extensão de solo e facilidade de acesso aos locais de produção. Essas condições e a carência alimentar da maioria do brasileiros torna a exploração desse potencial praticamente uma exigência social.

Para que a cadeia da piscicultura se torne uma atividade rentável aos produtores, há necessidade de que sejam tomadas medidas para que se possa fazer uma programação de produção e que este sistema de criação empregado na propriedade proporcione uma renda mensal ao produtor, dando estabilidade a atividade.

Como em qualquer outra atividade zootécnica, a maneira de tratar os animais em piscicultura é realizada considerando a biologia das espécies criadas (hábitos reprodutivo, alimentar, fases de vida, etc.), bem como 0 sistema de produção possível de ser praticado. Ao longo do desenvolvimento da piscicultura tem-se observado uma tendência ao uso de sistemas de cultivo cada vez mais intensivos.

A intensificação dos processos de produção busca alcançar maior produtividade em menores áreas, menor tempo e custo racionalizado no local, conforme as características mercadológicas de cada região. 


\section{II - REVISÃO TEÓRICA}

A aqüicultura é definida como a criação de organismos aquáticos (SILVA, 2003). Representa uma importante via de produção dos alimentos. Embora sua contribuição quando comparada ao aporte da agropecuária, ainda corresponde a uma pequena parcela das necessidades nutricionais da humanidade. Sendo este valor estimado em apenas $10 \%$ da proteína animal que o homem produz. Além disso, a aqüicultura, utilizando-se áreas inaproveitáveis para a produção agrícola e pecuária e reciclando seus subprodutos, produzindo alimento de alto valor nutricional (KUBITZA, 2000).

Com isso pode-se dizer que a carne de pescado constitui-se, portanto, de uma das mais eficiente e econômica via de transformação de energia e, sem provocar alterações profundas nos ecossistemas naturais, quando conduzidas de forma a obedecer ao manejo dos diferentes sistemas, e as limitações do ambiente (RIBEIRO, 2001).

Dentre da aqüicultura, destaca-se a piscicultura, caracterizada pela criação de peixes em cativeiros que é uma atividade que vem se desenvolvendo em um ritmo muito acelerado (aproximadamente 30\% ano) no Brasil. Este índice é muito superior ao obtido na maioria das atividades agropecuárias mais tradicionais. Isso se deve ao fato da piscicultura possuir uma boa lucratividade (PEZZATO, 1995). 


\subsection{Criação}

Existem diversos sistemas de criação de peixes hoje em dia. A escolha de um deles, ao se iniciar uma piscicultura, vai depender de fatores como: tamanho do investimento que se deseja empregar, disponibilidade de materiais, produtividade esperada, tecnologia, entre outros. (MATHEUS et al 1995).

No Brasil, as dificuldades na criação de uma espécie podem ser paliativamente resolvidas substituindo-a por outra espécie. Por exemplo, se não houve sucesso com a criação de pintado, buscar produzir outra espécie como pacu é uma solução. (ARANA, 2004).

O sucesso do empreendimento da piscicultura vai depender da finalidade quanto ao tipo de criação. Que pode ser produção de alevinos uma exploração em que peixes são passados a terceiros para serem recriados ou usados em povoamentos e repovoamentos de águas públicas ou particulares (KUBITZA, 2000).

De acordo com Xavier (1987), é considerada a fase mais lucrativa, entretanto, exige demanda favorável por alevinos na região, maior dedicação por parte do produtor, maior ocupação de mão-de-obra especializada e instalações de equipamentos mais complexos.

Segundo Martins,( 2003) a recria e engorda seria outro meto de criação de peixes, onde explora-se a capacidade de ganho de peso e crescimento dos animais, englobando a fase de alevinagem até o abate.

Menos lucrativa que a criação de alevinos, entretanto, caracteriza-se por exigir menor dedicação do piscicultor, necessitar de menor ocupação de mão-de-obra, sendo essa menos qualificada, necessitar de instalações e 
equipamentos menos complexos, podendo ser realizada em represas rurais, arrozais inundados, represas ou viveiros com ou sem integração com outras explorações agropecuárias e por ser dependente da oferta de alevinos, demanda e preço de pescado na região (SILVA, 2003).

\subsection{Escolha da Espécie}

Segundo Ribeiro, (2001) a escolha da espécie a ser criado depende do sistema de criação e da região da piscicultura. Levando-se em consideração a temperatura, topografia, tipo de solo, qualidade e quantidade de água disponível para renovação dos viveiros, preferência dos consumidores e 0 preço no mercado.

De acordo com Coelho, (1997) o aspecto que devem ser considerados na escolha das espécies a serem criadas seria: A espécie deve tolerar as condições mínimas e máximas do ambiente (adaptabilidade ás condições locais), deve ser de crescimento rápido e possuir alto poder de conversão alimentar e ser uma espécie resistente ao manejo de rotina e também as enfermidades mais comuns.

Arana, (2004) ainda comenta que a espécie deve ter aceitação no mercado e um preço competitivo e ter uma precocidade no crescimento e maturação sexual.

Existem no Brasil centenas de espécies de peixes de água doce que poderiam ser tranqüilamente trabalhadas. Hoje, no País, cultivam-se espécies nativas e exóticas (KUBITZA, 1997). 
Como espécies nativas de valor comercial pode-se citar o dourado, o tambaqui e o pirarucu. No entanto essas espécies não se reproduzem em tanques, são espécies de piracema (COELHO, 1997).

Segundo Ribeiro (2001), o crescimento da piscicultura no Brasil teve como base, espécies introduzidas que se reproduzem em tanques e permitem o cultivo controlado, que são as espécies exóticas sendo as mais conhecidas à tilápia do Nilo, a carpa e a Truta.

\subsection{Sistema de Criação}

Segundo Pezzato, (1995) existem diversos sistemas de criação nos quais os peixes podem ser criados de várias maneiras, dependendo das condições e qualidade da água, espécie, tipo de alimentação e aceitação de

mercado. É possível dividir o sistema de criação em extensivo, semi-intensivo, intensivo e super-intensivo.

\subsubsection{Sistema Extensivo}

Define-se como sistema extensivo a criação de peixes com interferência mínima possível nos fatores de produtividade, modificação mínima do ambiente natural, restringindo-se, praticamente, o povoamento inicial do corpo de água (HEPHER, 1985).

De acordo com Arana, (2004) as condições encontradas em quase toda propriedade rural do Brasil, seria coleção de água represada, onde muitas das vezes essa serve como bebedouro para animais, não se esgota com facilidade 
à presença de predadores e ausência práticas de adubação, calagem, arraçoamento.

Não há controle da produção apresenta uma produção anual de 200 a $400 \mathrm{~kg}$ por hectare de pescado, raramente é explorado nos aspectos econômicos. (OSTRENSKY 1998).

Consiste em um viveiro do tipo barragem para engorda de peixes, neste sistema, não se controla freqüentemente os parâmetros físicos, químicos e biológicos da água, devendo ser considerado no inicio do povoamento (KUBITZA, 2000).

\subsubsection{Sistema Semi-Intensivo}

Segundo Ribeiro, (2001) é o mais difundido no mundo todo. No Brasil, ainda é o sistema mais utilizado nas pisciculturas e se caracteriza pela maximização da produção de alimento natural (fito e zooplâncton,) que seve como principal fonte de alimento dos peixes. Nesse sistema nem sempre são controlados os parâmetros físicos, químicos e biológicos, sendo utilizada fertilização orgânica para área de recria (MATHEUS et al 1995).

Define-se como sistema de exploração em que o homem interfere em alguns fatores de produtividade, caracteriza-se pela possibilidade de esvaziamento total do criadouro, possibilidade de despesca, controle da reprodução dos animais estocados, ausência ou controle da predação, presença de prática de adubação (XAVIER, 1987). 
Pode ser praticado em viveiros de barragens ou derivações e ainda em reservatórios escavados e terrenos encharcados. A renovação de água se faz apenas para repor perdas por evaporação e infiltração (PINTO, 2003).

\subsubsection{Sistema Intensivo}

Define-se como o sistema intensivo criação que busca a produção máxima de peixe por unidades de volume de água, através do manejo de peixes de engorda (SILVA, 2003).

Segundo, Ostrensky (1998) esse sistema consiste em um represamento de água em pequenos tanques com alta densidade de estocagem e alta renovação de água. A barragem tem a finalidade principal de acumular água para o abastecimento dos viveiros. $\mathrm{O}$ abastecimento e o escoamento das águas são controlados, a captura dos peixes é mais fácil e o controle da fertilização é mais adequado.

Controlam-se todos os parâmetros físico, químicos e biológicos e o arraçoamento, nele adota-se a alimentação completa, com densidade de estocagem de 10.000 a 100.000 peixes/ha, há monitoramento total da qualidade de água e tanques construídos com planejamento (ARANA, 2004).

\subsubsection{Sistema Super-Intensivo}

De acordo com Pinto (2003), define-se como a criação de peixes em alta densidade e renovação total da água de cada 15 a 60 minutos, usa tanques pequenos com grande fluxo de água de boa qualidade. Exemplos: raceway e 
tanques-rede.

O sistema raceways são longos tanques construídos de alvenaria ou concreto, nos quais se utiliza grande vazão de água para a criação de peixes com densidade elevada (COELHO, 1997).

O sistema de criação de peixes em tanques-rede ou gaiolas tem uma renovação de água contínua, é uma das formas mais intensivas de criação atualmente praticadas e tem se tornado popular devido ao fácil manejo e rápido retorno do investimento; além de ser uma excelente alternativa para a produção de peixes em corpos d'água onde a prática da piscicultura convencional não é viável (OSTRENSKY 1998).

De acordo com Ribeiro, (1996) piscicultura em tanque-rede também possibilita o aproveitamento de ambientes aquáticos já existentes (oceanos, rios, grandes reservatórios, açudes entre outros).

\subsection{Viveiros e Tanques}

Segundo Ribeiro (2001), a classificação das estruturas pode ser baseada quanto ao tipo de sistema de produção, material empregado na construção e também quanto à forma como são construídos. Os viveiros são geralmente empregados em sistemas de produção extensivos a semiintensivos, ou bastante utilizados quando a produção primária é um fator bastante alvejado. Sua superfície é totalmente constituída por solo e por isso, requerem maiores cuidados com manutenção (COELHO, 1997).

Já, os tanques podem ser parcialmente ou totalmente revestidos ou construídos em alvenaria ou material artificial, podendo apresentar várias 
formas, inclusive circulares construídos acima do solo (ARANA, 2004).

Este tipo de construção permite maior movimentação do corpo d'água sem que ocorram maiores problemas quanto ao desgaste da estrutura. De maneira geral sua construção é mais onerosa, entretanto, requerem menores gastos com manutenção e permitem gerar maiores produtividades por área, uma vez que são estruturas utilizadas em sistemas intensivos e superintensivos de produção. (KUBITZA, 2000).

A forma e a dimensão de tanques e viveiros variam de acordo com a espécie cultivada, topografia do terreno, disponibilidade de água e o tipo de manejo a ser adotado na criação de peixes (MEURER et al, 2005).

Segundo Ribeiro, (1996) para a construção dos viveiros deve-se fazer a limpeza da área e viveiros retirando-se galhos, raízes e restos de vegetação. Devendo sempre respeitar a área de preservação permanente, no momento da definição do tamanho e dos formatos tanques. (ARANA, 2004).

Segundo Ribeiro, (2001) a profundidade de um tanque ou viveiro de piscicultura refere-se a sua lamina de água. Em viveiros, profundidades acima de 3,00 m são inaceitáveis, pois dificilmente a luz penetra, prejudicando a produção de alimentos naturais além de não realizar a fotossíntese. Devem sem em média de $1,5 \mathrm{~m}$ para facilitar as práticas de manejo e otimizando a utilização da água. (MATHEUS et al, 1995).

A estrutura do solo também deve ser considerada, podendo acontecer que, além de serem raso, eles apresente próximos a superfície, rochas com fraturas. Isto provoca enormes perdas de água por percolação, mesmo sendo os viveiros elevados sobre o terreno (XAVIER, 1987). 
De acordo com Pinto (2003), um dos fatores importantes a considerar é a textura dos solos. Os argilosos são mais indicados, em virtude do elevado grau de impermeabilidade e de serem ricos em minerais (ARANA, 2004).

Para Matheus et al (1995), os arenosos não são indicados para viveiros, pois são pobres e não retém água, neles podem ser construídos tanques. Solos sílico-argilosos, isto é formado por areias contendo cerca de $25 \%$ de argila, podem ser utilizado, contudo necessitam receber camada compactada de piçarra ( terra argilosa), a fim de reterem água (OSTRENSKY 1998).

\subsubsection{Sistema de Abastecimento e Drenagem}

O sistema de abastecimento deve ser construído com material (principalmente dos canais de abastecimento) condizente com as condições da topografia do terreno e volume de água, de modo a garantir máxima oxigenação e evitando danos erosivos (COCHE, 1993).

De acordo com Pinto (2003), o transporte da água aos viveiros poderá ser efetuado por canalizações fechadas ou a céu aberto, através de canais escavados, revestidos ou não com lona plástica ou, também, através de canais construídos em alvenaria.

A água deverá abastecer os viveiros, na sua porção superficial, através de canos posicionados ao meio do talude, a uma altura mínima de $30 \mathrm{~cm}$ acima da lâmina d'água. O controle da quantidade de água poderá ser efetuado através de registros de gaveta ou por caixas tipo comporta (XAVIER, 1987).

O sistema de drenagem pode ser do tipo cachimbo, ou seja, composto por tubulação de PVC e joelho articulado com diâmetro proporcionalmente 
maior que a vazão local, para que o viveiro possa ser devidamente esvaziado quando necessário em qualquer tempo (RIBEIRO, 2001).

Segundo, Ostrensky (1998) Comporta tipo monge deverá ser construída em concreto ou alvenaria e instalada ao meio da porção final do viveiro. Tal aparato irá contribuir para regular a altura da água no viveiro, possibilitando a drenagem constante na porção inferior, sem prejudicar o nível de profundidade.

Platô de drenagem, trata-se de uma calçada construída em concreto, com $7 \mathrm{~cm}$ de espessura, instalada à frente do monge para facilitar o manejo durante a drenagem total dos viveiros (MEURER et al., 2005).

Para Matheus et al (1995), o canal de drenagem tem que ter o cano de descarga do monge, que deverá atravessar o talude, na sua porção inferior, despejando a água da drenagem em um canal, que irá conduzi-la para um ponto de despejo em nível inferior ao dos viveiros, podendo ser constituído por algum córrego ou rio. Tal canal deverá ser escavado na terra e protegido, nos pontos de drenagem, por revestimento em concreto.

\subsection{Manejo dos Tanques}

Segundo Ribeiro, (2001) o manejo é principalmente realizado em viveiros. Estas práticas visam garantir maior durabilidade da estruturas e também melhores condições de produção, garantindo maiores taxas de produtividade. 


\subsubsection{Qualidade da Água}

Como toda atividade tem sua matéria prima essencial, a Piscicultura tem na água sua maior necessidade e na maioria das pisciculturas o fator limitante no aumento de produtividade. A água é o meio onde os peixes obtêm oxigênio para sobrevivência e crescimento, e é também onde os peixes soltam seus resíduos orgânicos alterando assim sua qualidade (Silva, 2003).

Um fator muito importante para a piscicultura, essencial para uma boa produção de peixes, é sem dúvida a qualidade da água em que o cultivo será realizado.

\subsubsection{Temperatura}

De acordo com Castagnolli,(1986) os peixes são ectotérmicos, ou seja, a temperatura do seu corpo é influenciada pelo ambiente, este fator agirá diretamente no desenvolvimento do animal, pois existem temperaturas ideais para alimentação, reprodução, resistência a doenças para cada grupo de peixes.

Também está relacionado com o oxigênio dissolvido, pois quanto maior a temperatura menor será a quantidade de oxigênio dissolvido (RIBEIRO, 2001).

Segundo Pezzato, (1995) os peixes de águas tropicais geralmente vivem bem com temperaturas entre $20-28^{\circ} \mathrm{C}$ e seu apetite máximo será entre $24-28^{\circ} \mathrm{C}$; entre $20-24^{\circ} \mathrm{C}$, eles se alimentam bem, mas abaixo desse 
patamar $\mathrm{o}$ apetite decresce rapidamente e acima de $28^{\circ} \mathrm{C}$ perdem-no totalmente, podendo ocorrer mortalidade em temperaturas superiores a $32^{\circ} \mathrm{C}$.

\subsubsection{Oxigênio dissolvido}

De acordo com Castagnolli,(1986) é o gás mais importante para os peixes, o produtor deve dar uma melhor atenção a este fator, pois o oxigênio é consumido de diversas formas: decomposição de matéria orgânica; oxidação de metais e respiração.

Para Matheus et al (1995), deve-se observar a quantidade e a qualidade da água que será utilizada para se iniciar uma piscicultura, pois se não tiver o oxigênio necessário a disposição, o produtor deve se utilizar de alguns artifícios para suprir essa necessidade, como: a utilização de filtradores biológicos, oxigenadores e aeradores.

O horário mais propício para fazer o controle de oxigênio dissolvido, é logo pela manhã, devido ao fato de que a noite é o pico de consumo de oxigênio, pois ao entardecer a atividade fotossintética diminui rapidamente dando lugar aos processos de respiração (RIBEIRO, 2001).

\subsubsection{Gás Carbônico}

Segundo Boyd, (2004) é um gás que deve ser controlado, pois seu excesso pode provocar asfixia, com os animais subindo à superfície para otimizar suas trocas gasosas além da diminuição do desempenho do plantel (afetando o crescimento, ganho de peso, aumento do estresse e taxas de 
conversão alimentar, e maior suscetibilidade aos patógenos).

Para Ostrensky (1998) é preciso estar atento com o acúmulo de matéria orgânica e com dias nublados, que são momentos propícios ao aumento da concentração de gás carbônico.

\subsubsection{Transparência}

A transparência é medida com o disco de Sechi (MEURER et al., 2005). Este é mergulhado e observa-se a profundidade em que este pode ser visto com nitidez (ARANA, 2004).

De acordo com Pinto (2003), o padrão de transparência ideal não é muito bem estabelecido, mas a média gira em torno de 40 à $60 \mathrm{~cm}$. O nível mínimo de transparência indica que água está com excesso de matéria orgânica (provocando uma cor esverdeada), diminuindo assim os níveis de oxigênio dissolvido e também significa que água está com muita argila (água barrenta) o que pode ser prejudicial aos peixes, grudando nas brânquias dificultando a respiração.

Para Coelho (1997), caso a água seja muito límpida (ultrapassando os $60 \mathrm{~cm}$ recomendados), há uma maior propensão ao aparecimento de macrófitas, que são vegetais superiores que podem estar enraizados ou não, totalmente submersos ou flutuando com raízes submersas as quais irão competir com os peixes pelo oxigênio dissolvido e podem dificultar o manejo nos viveiros. 


\subsubsection{Potencial Hidrogênio $(\mathrm{pH})$}

Segundo Pezzato, (1995) esta é uma medida que expressa acidez ou a alcalinidade de uma solução e é um parâmetro muito importante nos ambientes aquáticos, pois pode ser causa de muitos fenômenos químicos e biológicos, como por exemplo, o pH alcalino que é responsável por uma maior porcentagem de amônia não ionizada.

Para Matheus et al (1995) pode ser conseqüência de outros fenômenos, basicamente é influenciado pelas concentrações de íons $\mathrm{H}^{*}$ e $\mathrm{OH}-$, e também por sais, ácidos e bases que ocorram no meio, e abundância de fitoplâncton nos tanques de cultivo.

Esta medida possui um profundo efeito sobre o metabolismo e processos fisiológicos de peixes assim como de todos os organismos aquáticos (CASTAGNOLLI, 1986). As águas com valores que compreendem a faixa de 6,5 a 9,0 são as mais adequadas, abaixo de 6,5 diminuem os processos reprodutivos, e os pontos letais de acidez e alcalinidade são de pH 4 e pH 11, respectivamente (BOYD, 2004).

Para Ribeiro, (2001) nota-se que a água precisa de um monitoramento regular, pois o excesso de algas, vegetais e fitoplâncton provocam acidificação. Quando as condições de pH não são favoráveis à espécie cultivada ou existem muitas oscilações neste fator, os animais correm o risco de sofrerem irritações dérmicas, hemorragias, hipersecreção de muco, patologias branquiais e até mesmo morte (MEURER et al., 2005). Essas modificações também levam os peixes ao estresse, deixando-os suscetíveis a outras doenças (COCHE, 1993). 


\subsubsection{Alcalinidade}

A alcalinidade é a capacidade da água de neutralizar ou tamponar ácidos a ela adicionados, determinada pelos níveis de dissolução de carbonatos e bicarbonatos e é medida pela quantidade de bicarbonatos de cálcio (YANCEY, 1983). Quanto mais alcalina for a água, mais íons carbonato e bicarbonato ela conterá e mais difícil será fazer o seu pH variar. Para o bom desenvolvimento de um cultivo, a água deverá apresentar uma alcalinidade igual ou maior que 20mg/l (COCHE, 1993).

\subsubsection{Calagem e Adubação}

De acordo com Pinto (2003), a calagem seria um procedimento que visa manter boas condições para obtenção da produtividade primária e também manter o pH $(7,0)$ da água em níveis adequados para o bom desenvolvimento das espécies aquáticas.

Para Arana, (2004) a quantidade a ser utilizada depende entre outras coisas das condições químicas da água e das características (relação argila/areia) do solo. Podem ser utilizados vários produtos com este fim, como por exemplo: cal virgem, óxido de cálcio, carbonato de cálcio, calcário calcítico e dolomítico (RIBEIRO, 2001).

De acordo com Ribeiro (2001) as quantidades que podem ser empregadas na calagem são: A calagem deve ser realizada com os viveiros vazios, e depois de cheios, deve-se aguardar um período de 15 a 20 dias para o povoamento.

Segundo Boyd, (1990) além da função do controle da pH, sabe-se que a 
cal virgem apresenta função de esterilização do meio em que é a aplicado. Portanto, este procedimento pode ajudar a evitar problemas relacionados à sanidade dos peixes.

Segundo, Ostrensky (1998) o principal intuito da prática de fertilização é o de propiciar durante o cultivo, condições adequadas ao desenvolvimento do plâncton e permitir desta forma, maior produtividade do cultivo.

A adubação pode ser realizada pela utilização de adubos orgânicos e/ou químicos. Entretanto, cada sistema apresenta suas vantagens e desvantagens. (COCHE, 1993).

Para Coelho, (1997) a fertilização química, é mais indicada quando se pretende disponibilizar com maior controle e rapidez nutrientes no meio aquático, já a adubação orgânica proporciona uma menor velocidade, entretanto, deve-se ter cuidado neste tipo de prática devido à grande quantidade de material orgânico despejado nos viveiros, podendo prejudicar significativamente a qualidade da água.

Desta forma, a melhor prática de fertilização dos viveiros e tanques é mesclar os dois tipos de matérias baseando-se exclusivamente na quantidade de nutrientes a serem disponibilizados no meio aquático para garantir boa produção primária ( MEURER et al., 2005).

As recomendações de acordo com Xavier (1987) são: Adubação inicial: $1500 \mathrm{~kg}$ esterco (suíno, bovino, aves), $60 \mathrm{~kg}$ super fosfato simples e $30 \mathrm{~kg}$ de superfosfato triplo por hectare. Adubação de manutenção: 1000 kg esterco, 40 $\mathrm{kg}$ superfosfato simples e $20 \mathrm{~kg}$ de superfosfato triplo.

Para Ribeiro, (2001) esta adubação deve ser realizada mensalmente sendo que a produtividade primária deve ser controla pela verificação da 
transparência da água através do uso do disco de Secchi que deve ficar entre 30 e $45 \mathrm{~cm}$. Caso o valor averiguado seja superior a $45 \mathrm{~cm}$ a adubação de manutenção deve ser realizada.

\subsubsection{Densidade de Estocagem}

$\mathrm{Na}$ aquicultura intensiva, a densidade em que uma espécie pode ser estocada é um importante fator na determinação da viabilidade econômica (Kubtiza, 1999). Uma maior densidade de estocagem permite um menor custo de produção por peixe, desde que não haja redução substancial na taxa de crescimento e que a sobrevivência seja satisfatória (SILVA, 2003).

Na maioria das espécies investigadas, tem sido encontrada uma relação inversa entre densidade de estocagem e taxa de crescimento (COCHE, 1993). Contudo, observa-se que a densidade de estocagem mais adequada varia com a espécie, o tamanho comercial, o sistema de criação utilizado e a idade de estocagem dos peixes. Ela é determinada também por fatores exógenos, como temperatura, luz e taxa de alimentação (RIBEIRO, 2001).

De acordo com Pinto (2003), é importante considerar também a biomassa final projetada e sua relação com a capacidade de suporte do sistema, lembrando que a densidade biológica ótima não será necessariamente a melhor em termos econômicos.

De acordo com Silva (2003), é possível a criação inicial intensiva de larvas de peixes tropicais de água doce em condições controladas, sendo recomendadas densidades entre 15 e 30 larvas/L.

De acordo com Ribeiro (2001) a densidade de povoamento dos peixes 
normalmente ocorre de acordo com o tipo de cultivo. Cultivo extensivo - 1 peixe para cada 10m2; Cultivo semi-intensivo - 5 peixes para cada 10m2; Cultivo intensivo - 1 a 3 peixes por metro quadrado.

Para Matheus et al (1995) utilização de tanques-rede para criação de machos de tilápia são estocados de 50 a 100 alevinos/m3 em gaiolas de volume maior que $5 \mathrm{~m} 3$. Para gaiolas pequenas (mais eficientes por unidade de volume devido a maior facilidade para a troca de água) a taxa de estocagem pode chegar até 300 alevinos/m3.

\subsubsection{Alimentação}

Segundo, Ostrensky (1998) para se obter sucesso na piscicultura é fundamental a administração de uma alimentação adequada aos peixes. A alimentação tem efeito direto na sobrevivência, no crescimento e na produção.

De acordo com Pinto (2003), o requerimento de nutrientes pelos peixes para seu crescimento, reprodução e/ou outras funções fisiológicas é similar à qualquer exigência pelas outras espécies animais. Portanto os peixes necessitam consumir minerais, vitaminas, proteínas, fontes de energia, entre outros nutrientes engajados como fatores responsáveis pelo crescimento, desenvolvimento e ganho de peso das diferentes espécies (SILVA, 2003).

Segundo, Ostrensky (1998) para uma perfeita interação metabólica e conseqüente eficiência de aproveitamento do alimento ofertado, o valor nutricional de uma dieta não está baseado somente na sua composição alimentar ou bromatológica, mas também na quantidade de nutrientes presentes na mesma, que o peixe pode absorver e utilizar, suprindo assim suas 
exigências nutricionais para manutenção e produção (NRC,1993).

Para Arana, (2004) existem dois tipos de alimentos: Natural e Artificial. Os alimentos naturais são aqueles produzidos no viveiro e que são consumidos pelos peixes os fitoplâncton (algas), zooplâncton (microorganismos animais ) e matéria orgânica morta (MEURER et al., 2005).

Segundo Boyd, (2004) os alimentos artificiais são as rações balanceadas para peixes ou similares, extrusada, peletizadas ou em pó e todos os subprodutos agropecuários locais que o piscicultor possa oferecer aos peixes, a exemplo de raízes, grãos e farelos, verduras, legumes e frutas.

A frequência de arraçoamento necessária para o bom desenvolvimento do peixe varia principalmente conforme a espécie, idade, qualidade da água e temperatura. Espécies carnívoras podem ter menor freqüência de arraçoamento em relação às onívoras e, conforme aumenta a idade do peixe, a maior freqüência de arraçoamento não traz benefícios significativos ao seu crescimento (KUBITZA, 1997).

\subsection{Despesca}

De acordo com Silva (2003), pode ser feita parcelada ou totalmente no primeiro caso, realizam-se varias pescarias, utilizando-se rede de arrasto ou de espera, tarrafas ou anzóis e quando restarem poucos peixes no viveiro este é esvaziado e todos os indivíduos capturados.

$\mathrm{Na}$ despesca total dos peixes de engorda, o viveiro é esvaziado e todos os peixes capturados para a comercialização. No esvaziamento do viveiro 
deve-se ter cuidado com o sistema de drenagem para que por ele os peixes não escapem (SILVA, 2003).

A despesca na larvicultura é realizada baixando-se o nível de água dos tanques, através da abertura do registro situado na parte inferior (abaixo do tanque) para que a água saia por gravidade (COCHE, 1993).

\subsection{Transporte}

Segundo Alexandrino, (1998) a grande maioria das propriedades piscícolas em algum momento necessita fazer uso do transporte de peixes, já que mais alevinos precisam chegar para iniciar o novo ciclo produtivo ou então o peixe gordo precisa ser comercializado, destinados para o abate.

Para Teixeira, (1991) transportar peixes não é tão fácil quanto parece. É preciso ter conhecimentos a respeito da fisiologia dos animais, além de possuir equipamentos e veículos de transporte adequados.

Segundo Pezzato, (1995) é recomendável que os peixes adultos e alevinos sofram jejum durante algum tempo antes de serem submetidos às condições de transporte, pois durante esse período haverá um esvaziamento do trato digestório dos animais, proporcionando uma diminuição na quantidade de dejetos na água de transporte.

Para Matheus et al (1995) os dejetos excretas dos peixes contribuem muito para piora a qualidade da água e na diminuição dos níveis de oxigênio.

O principal item a ser foco de atenção do transportador e do piscicultor é o oxigênio dissolvido na água (RIBEIRO, 2001).

De acordo com Pinto (2003), os alevinos devem ser transportados em 
sacos plásticos transparentes e resistentes, com um terço de água e dois terços de oxigênio insuflado no seu interior. Os sacos devem ser fechados com elástico para garantir uma amarra segura e eficiente (TEIXEIRA, 1991).

Para Coelho, (1997) os peixes adultos podem ser transportados em caminhões apropriados ou em sacos plásticos (quando a distância é curta e o transporte é de poucos animais), do mesmo modo ao já descrito para alevinos. Caixas d’água improvisadas, embora sejam usadas, não são ideais, pois há grande perda de oxigênio durante o percurso, o que certamente pode afetar negativamente os peixes (MEURER et al. 2005).

Os peixes podem ser transportados em água contendo cloreto de sódio (sal grosso) em concentração de 1 a $5 \mathrm{~g} / \mathrm{l}$. A adição de sal na água provoca um efeito compensador nas quedas de cloretos no plasma, que é uma das causas do estresse nos peixes(TEIXEIRA,1991).

Um dos fatores que podemos observar na prevenção do estresse póstransporte é o horário de realização deste (COCHE, 1993).

As recomendações de acordo com Xavier (1987) é que transportar os peixes seja feito nas primeiras horas do dia ou no final da tarde, quando as temperaturas são mais amenas, evitando-se o horário das 10 às $18 \mathrm{~h}$. Se a temperatura da água aumenta, o metabolismo dos peixes ficará mais acelerado, conseqüentemente necessitando um maior aporte de oxigênio e havendo uma piora na qualidade da água pela concentração de substâncias tóxicas (RIBEIRO, 2001). 


\section{CONCLUSÃO}

O Estado de Rondônia possui grande potencial para o desenvolvimento da piscicultura, apresentando crescentes taxas de produção e produtividade. Isto se deve, em grande parte, ao aprimoramento e evolução tecnológica que a atividade vem sofrendo no estado.

A adequação do modelo antigo de piscicultura, para um modelo atual e rentável é de fundamental importância para a garantia da qualidade e produtividade do pescado oriundo de piscicultura, independente do sistema utilizado. A adoção de boas práticas de manejo e de um programa de gestão de qualidade é um caminho para o aumento da produtividade. Observa-se nessas áreas há uma mudança de atitude em uma parcela significativa de piscicultores, movidos pela necessidade de se obter maior eficiência produtiva. 


\section{REFERÊNCIAS BIBLIOGRÁFICAS}

ALEXANDRino DE PÉREZ, A. C. Manual de Prevenção de Doenças em Pisciculturas. São Paulo, Secretaria de Agricultura e Abastecimento, B. Téc. Inst.Pesca, 1998 n.23,45p.

ARANA L.V. Princípios Químicos de Qualidade da Água em Aqüicultura Florianópolis - Santa Catarina. 2004; p.33-70;

BOEGER, Walter. Técnica de manejo em piscicultura; 2000 p. 50-160;

BOYD, C. E.; QUEIROZ, J. F. 2004. In: CYRINO, J.E.P.; URBINATI, E. C.; FRACALOSSI, D. M.; CASTAGNOLLI, N. Tópicos especiais em piscicultura de água doce tropical intensiva. São Paulo: TecArt, 533 p.

Castagnolli, N.; Cyrino, J.E.P. Piscicultura nos Trópicos. 1 ed São Paulo: Manole, 1986,152 p.

Coche, A. G. Construcción de estanques para la piscicultura en la agua dulce: Estructuras y Trazados para exploraciones piscicolas. FAO, 1993 no.20/2, 213 p.

COELHO, S.R. Situação atual e perspectivas da indústria de rações para organismos aquáticos. In: SIMPÓSIO SOBRE MANEJO E NUTRIÇÃO DE PEIXES, Piracicaba, 1997, p. 102-116.

KUBITZA, F. Qualidade do alimento, qualidade da água e manejo alimentar na produção de peixes. In: SIMPÓSIO SOBRE MANEJO E NUTRIÇÃO DE PEIXES, Piracicaba, 1997, p. 63-116.

KUBITZA, F.. Tilápia, tecnologia e planejamento na produção comercial. Jundiaí, 2000 SP. 1ed. 285p.

Matheus, C. Eduardo et all;. Manual de Análise Limnológicas. Projeto "Aplicação do Conceito de Bacia Hidrográfica e Qualidade da Água em Estágio Técnico-Científico e Treinamento em Serviços Deprofessores de Ciências E Biologia”. Departamento de Hidráulica Saneamento: Centro de Recursos Hídricos e Escola Aplicada. USP. São Carlos, SP, 1995.

MEURER, F. et al. Fontes protéicas suplementadas com aminoácidos e minerais para tilápia do Nilo durante a reversão sexual. Revista Brasileira de Zootecnia, Viçosa, 2005. V. 34, n. 1, p. 1-6, 
OSTRENSKY, Antônio; Fundamentos e técnica de manejo; 1998 p. 221;

Pinto, A. Luiz; Saneamento Básico e Qualidade das Águas Subterrâneas. In: Moretti, Edvaldo C. E Calixto, Maria José M. S. (Org.); Geografia e Produção Regional: Sociedade e Ambiente. Campo Grande-MS, Editora da UFMS; 2003 p.11 A 55.

RIBEIRO, M.A.G. Reversão sexual de tilápias. Panorama da aqüicultura, 1996.v.6, n.37, p.14-16.1

RIBEIRO, R.P.;ZIMMERMAN, S. Fundamentos da moderna aqüicultura, Canoas : ULBRA, 2001, 190p.

Silva, Jaime F. E Jóia, Paulo R. Mapeamento da Bacia do Córrego João Dias, no Município de Aquidauana - MS, para fins de Planejamento Ambiental. In: Moretti, Edvaldo C. E Calixto, Maria José M. S. (Org.); Geografia e Produção Regional: Sociedade e Ambiente. Campo Grande-MS, 2003. Editora da UFMS; P. 101-124,

TEIXEIRA FILHO, A. R. Piscicultura ao Alcance de Todos. São Paulo, Nobel, 1991, $212 \mathrm{p}$.

Xavier, V.C.F. Cultivos Aquáticos: Peixes e Camarões de Água Doce. 1 ed. São Paulo, Nobel, 1986. 170 p.

WOYNAROVICH, E. Manual de piscicultura. Brasília; 1993

YANCEY, D.R.; Manual de Criação de Peixes, 1983. n.825, p.37-39, 